\title{
Historia mundial de la comunicación
}

Perceval, José María (2015). Historia mundial de la comunicación.

Madrid: Ediciones Cátedra.

\section{POR FLORENCIA ROVETTO}

florencia.rovetto@gmail.com Consejo NacionaldeInvestigacionesCientíficas y Técnicas (CONICET), Argentina

El último libro de José María Perceval condensa sus vastos conocimientos historiográficos sobre la mediatización humana. En conjunto, el texto se destaca por el despliegue de una gran capacidad explicativa, al tiempo que aporta un importante caudal de datos ordenados cronológicamente. Los acontecimientos descriptos recorren la "historia larga" del desarrollo de los medios de comunicación, comenzando con el proceso dehominización yla capacidad de cooperación mutual de las primeras comunidades hasta llegar a la globalidad de internet como plataforma de intercambios culturales en "un mundo que dedica más de la mitad del PIB mundial a través de los medios comunicación a desarrollar la industria del ocio, el entretenimiento, la cultura, la educación y la información” (2015, p. 285).

La metáfora del cuento de H. C. Andersen "Las zapatillas rojas" le sirve de preludio y epílogo a Perceval para recorrer el universo de la mediatización y dan cuenta de aquello que podemos definir como irremediablementehumano: imaginar futuros, transformar presentes y sufrir pasados.

Cada soporte nos permite extender nuestro mundo, ver más lejos, ir más allá. Cada soporteha permitido una mayor comunicación, un intercambio de informaciones cada vez más seguro, cada vez más extenso, cada vez más rápido, hasta llegar a una conexión que puede ser prácticamente instantánea y universal. Cada soporte de comunicación facilita (...) una comprensión mejor de lo que significa formar parte de la humanidad. Pero, al mismo tiempo, cada soporte implica un lenguaje que necesita un nuevo aprendizaje, unas prácticas que modelan un nuevo tipo de sociedad y un poder extendido que provoca unas determinadas luchas por su control (Perceval, 2015, p. 10).

La estructura general del libro presenta ocho capítulos en los cuales el autor relata la irreductible aventura humana de comunicarse. El primer capítulo está dedicado a la "Etapa oral-gestual", donde revisa los cambios y las adaptaciones 
físico-funcionales de un grupo de mamíferos (débiles e inadaptados) que, siete millones de años atrás, para pervivir, reproducirse y expandirse, necesitaron la ayuda cooperativa de su grupo, estableciendo estrategias comunicativas cada vez más complejas.

En este primer capítulo Perceval discute con los mitos ilustrados sobre la superioridad humana y con el darwinismo justificador de muchas dominaciones, afirmando que "es la debilidad, y no la fuerza, la que provoca el éxito de la especie humana” (2015, p. 13). Además, pasa revista a los aportes de la paleontología que dan cuenta de la modificación de la estructura del ojo (para ver en colores), la liberación de las extremidades superiores y de la cara (cabeza y cuello) que dio paso a la gesticulación, a la modulación del sonido y, con ello, a los primeros esbozos de la trasmisión cultural. En este capítulo también recorrelos hallazgos arqueológicos que sitúan las primeras manifestaciones del pensamiento simbólico hace 18.000 años: contar, figurar e imaginar dan paso a la creación de un espacio externo de representación y a la memoria del grupo (Dondis en Williams, 1992).

Una cuidadosa selección de hipótesis elaboradas a partir de aportes provenientes de la biología, la antropología y la semiótica le permiten a Perceval pasar revista por el desarrollo de la trasmisión del saber y la educación, el papel de las chamanes en los rituales, la magia y la experiencia estética como acceso al mundo de los relatos encarnados en la figura de "la abuela", la hembra menopaúsica de la especie que aumenta la capacidad para aprender nuevas habilidades y trasmitirlas, al tiempo que reclama más cooperación y comunicación del grupo (Hawkes, 2003). Luego se desliza por los orígenes de la jerarquización delas sociedades con la aparición de los monarcas sagrados, los tabúes, la segregación de carácter misógina, "la sublimación de las pulsiones eróticas en un culto al dolor y la muerte y la clara jerarquización de las relaciones homofílicas dentro del grupo" (Perceval, 2015, p. 47). Finalmente, el autor pone de relieve que el avance de la domesticación (de animales y plantas) en todo el planeta, así como el surgimiento de las pequeñas aldeas que conforman una red de sociedades urbanas primigenias, alrededor de templos-graneros gestionados y controlados por los nuevos monarcas sagrados, junto con los tabúes que regulan el acceso de la población a los excedentes, son los elementos que dan paso a la domesticación de pensamiento sin escritura, las redes internas de información y preparan el terreno para la ordenación de la "razón gráfica" (Goody, 1977, p. 52).

El segundo capítulo está destinado a la "Etapa gráfica" dela comunicación; donde el número, la escritura y la imagen se convertirán en armas tan poderosas como los ejércitos y el metal para un conjunto sacerdotal y guerrero que gestiona templos y palacios y que se expande con voluntad de domino: "el poder se describe a sí mismo y describe a los otros" (2015, p.59). Aquí Perceval 
recorre las múltiples funciones de la escritura y su reproducción mediante los soportes exigidos por las culturas en diferentes territorios y de acuerdo a particulares condiciones de posibilidad. "De la piedra al papiro, del papiro al pergamino, del rollo al códice" (2015, p. 74), la etapa gráfica se extiende de oriente a occidente y, junto con ella, se precipitan la invención del Estado, la moral, la retórica. En este capítulo se destaca el uso de las fuentes historiográficas que ponen en escena un largo proceso de cambios técnicos e ideológicos que operan favoreciendo todo tipo de tensiones entre lo nuevo y lo viejo, lo religioso y lo pagano, lo impreso y el rumor, lo peregrino y lo urbano, el analfabetismo y la lectura.

El tercer capítulo está dedicado enteramente a "La imprenta", recorriendo su derrotero con bases orientales (papel y tinta) que se consolidan con mejor suerte en Europa gracias a las condiciones comerciales, la organización social en las nuevas ciudades (1300-1500) y el fortalecimiento de las redes de comunicación. Las figuras del escritor y el librero-impresor son funciones unidas en esos primeros tiempos de la imprenta, combinándose en un juego de tres elementos con dinámicas propias y a veces contradictorias: autor, obra y público (2015, p. 104). A partir de allí se desplegará un cúmulo de distinciones que siguen condicionando las explicaciones hasta nuestros días sobre el problema de la recepción literaria. La complejidad del panorama de la recepción crece aún más en la medida en que se incorporan los públicos lectores de la prensa.

Antes de entrar de lleno en el campo de la industria cultural que desarrolla en el siguiente capítulo, Perceval da cuenta del impacto de las reformas religiosas, la homogenización de la lengua, la sociedad cortesana "como laboratorio que modela las costumbres y los comportamientos para el control y el autocontrol personal necesarios a todo proceso" de masas (Elias, 1975, p. 115). En este recorrido condensa muchos y diversos interrogantes sobre los elementos coincidentes entre la "revolución" y la "Ilustración", calibrando las dimensiones de ruptura o extensión fraguadas en la construcción de "lo moderno" (Chartier, 1990).

\footnotetext{
La invención del hombre moderno es una mezcla de educación, como represión asumida, y respecto a la ley, como represión exterior impuesta, todo ello canalizado por un nuevo espacio inédito, el espacio de la opinión pública que regula si es legítimo o no este sacrificio. Este espacio modela los comportamientos a través de la ficción, las actitudes a través de las modas, las costumbres ordenando la tradición nacional en lo que es correcto y no es correcto, y determina las acciones diarias a realizar desde la tribuna de la prensa. Los gobiernos van a necesitar a partir de este momento la aprobación constante de unos medios de comunicación que se arrogan el papel de representantes de la opinión pública. Pero, ¿es realmente la prensa la expresión de la opinión pública? (2015, p. 140).
} 
El cuarto capítulo, "Etapa industrial”, continúa con la reconfiguración del mundo occidental a partir de las revoluciones (francesa y americana) y describe el paisaje intervenido por la comunicación estatal, que junto con innovaciones como el telégrafo óptico permitirán la fusión del territorio nacional y proporcionarán una lengua universal para trasmitir informaciones. Para dar cuenta de estos cambios, Perceval recorre las reformas territoriales, la invención de unanimidad nacionalista, la guerra total, el vapor, los terrorismos y socialismos, así como la consolidación del capitalismo a nivel mundial. Todos estos procesos, para el autor, están bañados por la obsesión en el control de las comunicaciones y sus "transportes", el control de los contenidos y la identidad de quien los trasmite. Aquí sus explicaciones en torno a la gestión de los medios de comunicación -después de cuatro siglos de imprenta, prácticas de consumo cultural y sociabilidad política a partir del impreso- hacen referencia a una gran cantidad de fuentes historiográficas que permiten recorrer las transformaciones de soportes y funciones de la mediatización: las continuidades entre la prensa de partido y la prensa publicitaria, el invento de la intimidad y la industrialización del ocio y la privacidad, la aparición de la imagen fija y su reproducción.

Los siguientes dos capítulos son "Período de la electricidad" y "Etapa de la Sociedad de Bienestar". Aquí el autor detalla aspecto de la industria cultural de masas, que trasformó el pueblo en público. El teléfono, el gramófono y la radio introducen voces extrañas en los hogares, mientras que el cine hipnotiza entronizando a líderes y famosos. Las transformaciones producidas durante la etapa del "bienestar" se plantean en el trabajo como una notoria intensificación cuantitativa y cualitativa de la forma del mensaje y su reconocimiento, en el marco de cambios culturales y políticos de gran significación histórica. Al respecto, el pasaje de la relevancia social de los creadores a los intérpretes en las manifestaciones musicales y artísticas de la mano de una nueva juventud del bienestar supone, a su vez, el pasaje de la preeminencia del contenido a los modos con los que las sociedades industriales producen comunicabilidad a través de actos "espectaculares". La espectacularización del hecho social trasmitido en la noticia de los grandes medios comunicativos se traslada a la política con la masificación de la televisión; en donde, como agrega Perceval, "la intimidad es trasmitida como espectáculo".

Esta etapa de benefacción y de crecimiento económico produce una generación autónoma de sus mayores, resultante del baby boom, quehará del mercado un ámbito de diferenciación y consumo. Pero crea a su vez, y allí los medios de comunicación masiva y la publicidad de masas cumplen un rol principal, nichos de mercado etario, para la niñez, la juventud y la vejez.

El período de "Crisis del Estado de bienestar" (1975-2014) y la actualidad presentada como "Etapa digital" cierran la égida interpretativa del autor en los últimos dos capítulos. Como sucede con la totalidad del viaje que nos propo- 
ne el autor a través del tiempo, a los cambios estructurales que modifican las relaciones sociales les corresponde una diversa cantidad de formas de anclar el proceso comunicativo con sus diversos soportes y con consecuencias que moldean, cada vez más, los valores y acciones del cuerpo social.

La etapa neoliberal o de reacción frente al estado de bienestar es el período del imperio de las grandes corporaciones mediáticas multinacionales, creadoras de una nueva configuración sociopolítica a escala planetaria, en donde "la realidad" sucede a través de las pantallas en sus diferentes formatos. La etapa de la crisis contemporánea del Estado de Bienestar es el momento de la individualización de un mundo propio y de la soledad del walkman y la telefonía móvil; pero, a su vez, la comunicación se globaliza, conectándonos mundialmente. La creación de la idea de la aldea global-que identifica el tiempo de la gran masa de personas interconectadas- es también el momento donde la vinculación comunicativa está más mediada por las pantallas: la socialización por medio de la interfaz digital y, a través de múltiples soportes, emula un plató de televisión como plataforma mediatizada de contacto y conocimiento.

La "Etapa digital" propone la interpretación de un excurso aún abierto a nuevos impactos sociales. Internet, la comunicación satelital y el soporte técnico de la fibra óptica se configuran creando un mundo virtual paralelo al mundo real; también amplifican la confusión y el interrogante acerca de dónde reside la realidad, tal como formula Žižek (2005). La paradoja de visibilidad e invisibilidad absoluta de los conectados a la red, la creación de la noticia desde un espacio multicéntrico y en permanente construcción, la rapidez y simultaneidad de distintas estructuras noticiosas que destronan a la noticia periódica del formato papel, y el transporte a escala global de la construcción informativa a través de las redes, son objetos de un minucioso análisis que Perseval desarrolla en esta última etapa.

Finalmente, se pude decir que el recorrido cronológico - con intensos parámetros diacrónicos- destaca que el aparato técnico de las distintas etapas de la comunicación social no es el elemento determinante de este recorrido, sino que está determinado por el contexto sociocultural y las estructuras económicas que lo hicieron posible. De esta manera, el esfuerzo de José María Perceval por aunar la comunicación humana en distintas etapas históricas es, en última instancia, la expresión y el resultado de la lucha social y las disputas por globalizar las comprensiones de lo Otro, de lo distinto, y no de una teleología descorporizada de la técnica y su impacto en la sociedad. 


\section{REFERENCIAS}

Chartier, R. (1990). Les origines Culturelles de la Révolution Française. Paris: Seuil.

Elias, N. (1975). La dynamique d'Ocident. Paris: Calmann-Lévy.

Dondis, D. A. (1992). Signos y símbolos. En Raymond Williams (editor), Historia de la comunicación (pp. 363-366). Barcelona: Bosch/Icaria.

Goody, J. (1977). La raison graphique. La domestication de la pensée sauvage. Paris: Minuit.

Hawkes, K. (2003, mayo-junio). Grandmothers and the Evolution of Human Logevity. En American Journal off Human Biology, 15 (3), pp. 380-400.

Žižek, S. (2005). Bienvenidos al desierto de lo real. Madrid: Akal.

Florencia Rovetto es Doctora en Periodismo y Ciencias de la Comunicación por la Universidad Autónoma de Barcelona (UAB), España, e Investigadora del Consejo Nacional de Investigaciones Científicas y Técnicas (CONICET), Argentina. Se desempeña como docente de grado y posgrado en distintas universidades argentinas y es miembro del Centro de Investigaciones en Mediatizaciones (CIM) y del Centro de Investigaciones Feministas y Estudios de Género(CIFEG) dela Universidad Nacional de Rosario(UNR), ambos con asiento en la Universidad Nacionalde Rosario(UNR), Argentina. 